\title{
Políticas públicas ambientais: uma revisão sistemática
}

Este artigo de revisão sistemática objetivou analisar o que está sendo investigado no campo das políticas públicas ambientais. Os procedimentos metodológicos utilizados foram: descritivo, bibliográfico, com abordagem qualitativa. A coleta abrangeu as bases eletrônicas de dados Emerald, Scielo Citation Index, Science Direct e Scopus (Elsevier). As palavras chaves utilizadas foram 'políticas públicas ambientais' e 'meio ambiente e políticas públicas', sendo que esses termos também foram pesquisados em inglês e espanhol. A busca foi realizada por meio dos operadores booleanos, resultando em 22 (vinte e dois) artigos publicados nas bases. Desse total, foram excluídos os artigos repetidos e aqueles que não contemplavam o foco desta pesquisa. Após a aplicação dos Testes de Relevância, foram selecionados 12 (doze) artigos que compuseram a amostra final. Os resultados apontaram que, dentro das políticas públicas, os estudos concentram-se em discussões sobre desenvolvimento sustentável, formulação e implementação das políticas públicas, bem como a gestão ambiental. Também se abordou a legislação ambiental e a participação social para o desenvolvimento de políticas ambientais. A principal conclusão consiste em afirmar que as publicações relacionadas às políticas públicas ambientais no Brasil ainda são incipientes e demandam de mais pesquisas para consolidar esse campo de conhecimento.

Palavras-chave: Políticas Públicas; Políticas Públicas Ambientais; Meio Ambiente e Políticas Públicas.

\section{Environmental public policies: a systematic review}

This systematic review article aimed to analyze what is being investigated in the field of environmental public policies. The methodological procedures used were descriptive, bibliographic, with a qualitative approach. The collection included the electronic databases Emerald, Scielo Citation Index, Science Direct and Scopus (Elsevier). The key words used were 'environmental public policies' and 'environment and public policies', and these terms were also searched in English and Spanish. The search was performed through Boolean operators, resulting in 22 (twenty-two) articles published in the databases. Of this total, the articles were repeated and those that did not contemplate the focus of this research. After applying the Relevance Tests, 12 (twelve) articles were selected that composed the final sample. The results pointed out that, within public policies, the studies focus on discussions on sustainable development, formulation and implementation of public policies, as well as environmental management. Environmental legislation and social participation for the development of environmental policies were also discussed. The main conclusion is that the publications related to environmental public policies in Brazil are still incipient and require more research to consolidate this field of knowledge.

Keywords: Public Policies; Environmental Public Policies; Environment and Public Policy.

Topic: Planejamento, Gestão e Políticas Públicas Ambientais

Reviewed anonymously in the process of blind peer.
Received: 02/01/2021 Approved: 29/01/2021
Karla Nadal (iD)

Universidade Estadual do Centro-Oeste, Brasil

http://lattes.cnpq.br/2873018020034907

http://orcid.org/0000-0002-3413-0140

karla_nadal@hotmail.com

\section{Marli Kuasoski (iD)}

Universidade Estadual do Centro-Oeste, Brasil http://lattes.cnpq.br/4243331301403766 http://orcid.org/0000-0002-5996-8556 marlikuasoski@hotmail.com

Luis Paulo Gomes Mascarenhas (iD)

Universidade Estadual do Centro-Oeste, Brasil http://lattes.cnpq.br/4187937070880705 http://orcid.org/0000-0002-7762-2727 Imascarenhas@unicentro.br

\author{
Ronaldo Ferreira Maganhotto (D) \\ Universidade Estadual do Centro-Oeste, Brasil \\ http://lattes.cnpq.br/4031550783871062 \\ http://orcid.org/0000-0003-0659-1481 \\ ronaldomaganhotto@gmail.com

\section{Sérgio Luís Dias Doliveira} \\ Universidade Estadual do Centro-Oeste, Brasil \\ http://lattes.cnpq.br/6877990196326427 \\ http://orcid.org/0000-0001-9957-225X \\ sdoliveira@unicentro.br
}

\section{Referencing this:}

NADAL, K.; KUASOSKI, M.; MASCARENHAS, L. P. G.; MAGANHOTTO, R. F.; DOLIVEIRA, S. L. D.. Políticas públicas ambientais: uma revisão sistemática. Revista Ibero Americana de Ciências Ambientais, v.12, n.1, p.680-690, 2021. DOI: http://doi.org/10.6008/CBPC2179$\underline{6858.2021 .001 .0054}$ 


\section{INTRODUÇÃO}

Embora existam muitas definições para o termo políticas públicas, todas convergem para um mesmo elemento central: o Governo (SOUZA, 2006). As políticas públicas estão relacionadas à atuação do governo que, visando alcançar objetivos pré-definidos, adota ações e estratégias a partir das quais se desenvolvem as inter-relações entre Estado, economia e sociedade.

Pode-se, então, resumir política pública como o campo do conhecimento que busca, ao mesmo tempo, 'colocar o governo em ação' e/ou analisar essa ação (variável independente) e, quando necessário, propor mudanças no rumo ou curso dessas ações (variável dependente). A formulação de políticas públicas constitui-se no estágio em que os governos democráticos traduzem seus propósitos e plataformas eleitorais em programas e ações que produzirão resultados ou mudanças no mundo real. (SOUZA, 2006)

Através das políticas públicas, o Estado pode intervir nas mais diversas áreas da economia: setores produtivos, mercado financeiro, relações internacionais, câmbio, etc. Da mesma forma, as ações governamentais interferem diretamente na sociedade, em questões como saúde, educação, emprego, moradia, meio ambiente, entre outras. As políticas públicas são desenvolvidas pelos governos com o objetivo de gerar crescimento econômico e desenvolvimento.

Vasconcellos et al. (1998) apresentam as diferenças conceituais nas definições de crescimento e desenvolvimento econômico. Para os autores:

Crescimento econômico é o crescimento contínuo da renda per capita ao longo do tempo, ou seja, é o processo pelo qual a quantidade de bens e serviços, produzidos por uma coletividade, tende a crescer mais rapidamente que ela. [...] Desenvolvimento econômico é um fenômeno mais global, que diz respeito às alterações da composição do produto e a alocação dos recursos pelos diferentes setores da economia, de forma a melhorar os indicadores de bem-estar econômico e social (pobreza, desemprego, desigualdade, condições de saúde, nutrição, educação e moradia).

A definição evidencia que o conceito de desenvolvimento é muito mais amplo do que crescimento. O termo crescimento está relacionado a aspectos econômicos da nação, como produção, renda nacional, isto é, indicadores predominantemente quantitativos. Por sua vez, para haver desenvolvimento é necessário que exista crescimento econômico, mas não unicamente (VASCONCELLOS et al., 1998).

O conceito de desenvolvimento abrange fatores não apenas quantitativos, mas também qualitativos, como distribuição de renda, emprego, saúde, educação, entre outros que expressam a elevação da qualidade de vida da sociedade. Dessa forma, não basta que a economia cresça, aumentando a produção e gerando mais renda. Se tal expansão for alocada de forma concentrada entre as diferentes classes sociais, o crescimento econômico não terá gerado desenvolvimento. Para haver desenvolvimento é necessário que a elevação do produto e da renda proporcione maior qualidade de vida para toda a sociedade.

Ao desconsiderar as questões qualitativas, as teorias pautadas apenas na ótica do crescimento econômico excluem também um importante elemento: o meio ambiente. Os primeiros modelos avaliavam a economia sem considerar os impactos que o crescimento econômico causa à natureza e, por consequência, à sociedade. Contudo, tais preocupações devem estar inseridas na concepção de desenvolvimento, uma vez que este se relaciona a aspectos qualitativos, que impactam na qualidade de vida da sociedade (VASCONCELLOS et al., 1998).

Conforme definições mencionadas, torna-se possível diferenciar claramente desenvolvimento de 
crescimento econômico. Sachs (2004) ressalta que "o crescimento é uma condição necessária, mas de forma alguma suficiente, para se alcançar a meta de uma vida melhor, mais feliz e mais completa para todos". Enquanto que os objetivos do desenvolvimento vão bem além da multiplicação da riqueza material.

Para o autor, "o conceito desenvolvimento sustentável, por sua vez, acrescenta uma outra dimensão - a sustentabilidade ambiental - à dimensão da sustentabilidade social" (SACHS, 2004).

A concepção de crescimento, que antes ocupava um lugar de honra, teve sua legitimidade questionada, por não contemplar as questões ambientais. Contudo, Sachs (2007) propõe que:

A aposta num desenvolvimento econômico e social contínuo, harmonizado com a gestão racional do ambiente, passa pela redefinição de todos os objetivos e de todas as modalidades de ação. $O$ ambiente é, na realidade, uma dimensão do desenvolvimento; ele deve ser, portanto, internalizado em todos os níveis de tomada de decisão.

Sachs (2004), desenvolvendo o conceito original de sustentabilidade ambiental, ressalta que "[...] é baseada no duplo imperativo ético de solidariedade sincrônica com a geração atual e de solidariedade diacrônica com as gerações futuras".

Para Guimarães et al. (2009), o conceito de desenvolvimento sustentável “[...] enseja mudanças de comportamento na forma como os seres humanos se relacionam com o meio ambiente, bem como no modo de formular, implementar e avaliar políticas públicas de desenvolvimento".

A partir dos conceitos discutidos, verifica-se que a implementação de políticas públicas eficazes também é um instrumento indispensável para a promoção de desenvolvimento. $O$ Estado deve estabelecer mecanismos que gerem crescimento e que canalizem seus resultados à promoção da qualidade de vida a toda a sociedade, o que inclui a adoção de estratégias que busquem soluções às questões ambientais.

Este estudo, de natureza qualitativa e de caráter descritivo e bibliográfico, surgiu a partir da seguinte indagação: o que se produz sobre políticas públicas ambientais?

Para a realização da pesquisa, foram levantadas produções científicas nas bases eletrônicas de pesquisa Emerald, Scielo Citation Index, Science Direct e Scopus (Elsevier), publicadas a partir de estudos realizados sobre o tema 'políticas públicas ambientais'. Para se obter uma busca mais ampliada, optou-se por não delimitar um período temporal.

As palavras chaves utilizadas foram 'políticas públicas ambientais' e 'meio ambiente e políticas públicas', em inglês, espanhol e português. A busca foi realizada por meio dos operadores booleanos, resultando em 22 (vinte e dois) artigos publicados nas bases. Desse total, foram excluídos os artigos repetidos e aqueles que não contemplavam o foco desta pesquisa. Após a aplicação dos Testes de Relevância, foram selecionados 12 (doze) artigos que compuseram a amostra final.

\section{REVISÃO TEÓRICA}

\section{Políticas pública}

A política pública, enquanto disciplina e campo de estudos, surgiu nos EUA, por volta da década de 50, com a denominação de Policy Science (FREY, 2000). A ênfase dada aos estudos de políticas públicas nos EUA recaía sobre as ações do governo, e não sobre o papel deste propriamente dito (SOUZA, 2006). 
Para analisar o conceito de políticas públicas, primeiramente, se faz necessário analisar três conceitos que estão intrinsecamente relacionados, polity, politics e policies. De acordo com Deubel (2010), polity está relacionada com a esfera pública como um todo; politics compreende a política enquanto cargo político; policies são as atividades resultante das políticas adotadas pelo governo, ou seja, conjunto de ações voltadas às ações públicas propriamente ditas.

Na concepção de Smith et al. (2009) a política pública é um produto da demanda, um curso de ação dirigido pelo governo como resposta para pressionar algum problema percebido; a política pública pode ser positiva (deliberada intencionalmente) ou negativa (decisão intencional de não agir).

Estudar políticas públicas é buscar compreender as iniciativas do governo na sociedade (MENY et al., 1992). As políticas públicas dizem respeito a um “[...] curso de ação, de programas de ações adotadas por uma pessoa, grupo ou governo, ou a série de princípios dos quais estão embasadas essas ações" (DEUBEL, 2010).

Políticas públicas dizem respeito à um “[...] fluxo de decisões públicas, orientado a manter o equilíbrio social ou a introduzir desequilíbrios destinados a modificar essa realidade" (SARAVIA, 2006). De acordo com essa decisão, pode-se dizer que as políticas públicas são estratégias direcionadas para modificar uma realidade social e sua última instância seria a de buscar a justiça social, a democracia, a manutenção do poder e o bem-estar das pessoas (SARAVIA, 2006).

Souza (2006) e Smith et al. (2009), analisando os conceitos de política pública, ressaltam que não existe uma única definição e, por mais variados que sejam os conceitos, estes buscam traçar uma abordagem geral do tema. No entanto, sejam os conceitos amplos ou mais condensados, Souza (2006) comenta que a variedade das definições presentes na literatura sobre políticas públicas tem todos um mesmo objeto, “[...] guiam o nosso olhar para o locus onde os embates em torno de interesses, preferências e ideias se desenvolvem, isto é, os governos".

Souza (2006) relaciona que "pode-se, então, resumir política pública como o campo do conhecimento que busca, ao mesmo tempo, 'colocar o governo em ação' e/ou analisar essa ação (variável independente) e, quando necessário, propor mudanças no rumo ou curso dessas ações (variável dependente)”.

No Brasil, o campo de investigação das políticas públicas é recente. Por volta dos anos de 1970 e início de 1980, época de transição do autoritarismo para a democracia, houve maior interesse pelo campo das políticas públicas (HOCHMAN et al., 2007). De acordo com Frey (2000) "Nesses estudos, ainda esporádicos, deu-se ênfase ou à análise das estruturas e instituições ou à caracterização dos processos de negociação das políticas setoriais específicas".

O estudo de Farah (2016) demonstra que a análise das políticas públicas no Brasil vem passando por transformações desde a sua ocorrência, na década de 1930. Isso significa que o olhar teve diferentes enfoques e diversos métodos de análise foram utilizados ao longo desses anos. A partir dos anos 2000, houve maior concentração de publicações e oferta de cursos voltados às políticas públicas, institucionalizando esse campo de estudos.

Percebe-se uma crescente expansão do conhecimento sobre políticas públicas, seja por uma maior 
concentração de eventos acadêmicos e profissionais, seja pelo crescente número de cursos de graduação e pós-graduação voltados à essa área. A sua disseminação em diversos campos de conhecimento, tem fortalecido o caráter multidisciplinar das políticas públicas, corroborando para a formação de profissionais e pesquisadores (BRASIL et al., 2016).

\section{Políticas públicas ambientais}

A política ambiental surgiu na segunda metade do século $X X$, em decorrência de importantes acontecimentos internacionais que influenciaram a evolução do tema no mundo e, consequentemente no Brasil. Os Estados Unidos foram o primeiro país que percebeu a necessidade do envolvimento do poder público nos problemas ambientais, ainda na década de 1960, com a elaboração da "Avaliação dos Impactos Ambientais" (AIA), formalizada em 1969. No Brasil, as questões ambientais existem desde 1950, porém foram aprofundadas somente a partir da década de 60 , em resposta às exigências do movimento internacional ambientalista, quando a crise ambiental entra em evidência (PECCATIELLO, 2011).

Monosowski (1989) descreve que a política ambiental brasileira foi caracterizada, até o ano de 1988, por quatro abordagens estratégicas básicas, sendo a administração de recursos naturais, o controle da poluição industrial, o planejamento territorial e a gestão integrada de recursos.

Na primeira fase, apontada a partir de 1930, foram elaborados muitos instrumentos legais que deram suporte à criação de áreas protegidas no Brasil (MONOSOWSKI, 1989).

A segunda etapa que ocorreu a partir de 1970, foi firmada no controle da poluição industrial e fortalecida principalmente pela Conferência das Nações Unidas sobre Meio Ambiente, realizada no ano de 1972, em Estocolmo. Ainda nesse período foi criada a Secretaria Especial de Meio Ambiente (SEMA), órgão coordenado pelo Ministério do Interior, especializado em assuntos ambientais (MONOSOWSKI, 1989).

Considerada como um desdobramento da segunda etapa, surgiu também em 1970, a abordagem estratégica de planejamento territorial, originada em decorrência da urbanização e do elevado crescimento das regiões metropolitanas, resultando na escassez de recursos naturais. Essa fase propiciou uma maior atenção à necessidade de ordenação territorial como ferramenta de uma política preventiva dos impactos sobre o meio ambiente (MONOSOWSKI, 1989).

O Comitê Especial de Estudos Integrados de Bacias Hidrográficas (CEEIBH) e leis metropolitanas de zoneamento industrial e de proteção de mananciais foram criadas legislações nesse contexto. Contudo, apesar dos avanços, as políticas ambientais restringiam-se às áreas urbanas, deixando as regiões rurais ao desdém (MONOSOWSKI, 1989).

A quarta fase, intitulada gestão integrada de recursos, inicia-se em 1981, com a criação da Política Nacional de Meio Ambiente, Lei no 6.938 de 31/08/81 que responsabiliza o Estado pelas ações ambientais; foi instituído também o Ministério de Desenvolvimento Urbano e Meio Ambiente, em 1985; nesse mesmo período foi criado o Conselho Nacional de Meio Ambiente (CONAMA), órgão consultivo e deliberativo que permitiu, apesar de limitada, a participação pública nas decisões, foi instituído ainda o Sistema Nacional de Meio Ambiente (SISNAMA), subordinado ao CONAMA (MONOSOWSKI, 1989). 
Na década de 80, diante de rediscussões das políticas nacionais e internacionais, surge o conceito de desenvolvimento sustentável, como "processo que permite satisfazer as necessidades da população atual sem comprometer a capacidade de atender às gerações futuras" (LEFF, 2006).

Essa definição ficou conhecida a partir da publicação do Relatório Brundtland (ONU, 1987), disseminado pela Comissão Mundial sobre Meio Ambiente e Desenvolvimento, criada pela Organização das Nações Unidas (ONU). O relatório foi elaborado com o objetivo de debater e sugerir procedimentos que articulassem o desenvolvimento econômico com a conservação ambiental.

Seguindo uma periodização dos acontecimentos, em 1988 foi promulgada a Constituição da República Federativa do Brasil, propondo em seu Art. 225, a formulação da preocupação e as bases para um Estado Socioambiental. A Lei de Crimes Ambientais (Lei no 9.605) foi implantada também no ano de 1988.

A partir da efetivação dessas políticas públicas, passou-se a reconhecer que o padrão de desenvolvimento em curso, cujo objetivo principal era o progresso econômico, apresentava situações impossíveis do ponto de vista biofísico quando projetado para o futuro (GUIMARÃES et al., 2009).

Reconhece-se que, para ser alcançado, o desenvolvimento sustentável depende de planejamento e do reconhecimento de que os recursos naturais são finitos. Esse conceito representou uma nova forma de desenvolvimento econômico, que leva em conta o meio ambiente.

Sachs (2007) destaca ainda que:

[...] os problemas de uso dos recursos naturais, de suprimento energético, de meio ambiente, de controle demográfico e de desenvolvimento só poderão ser corretamente percebidos quando examinados em suas relações mútuas, o que implica um quadro conceitual unificado de planejamento. Entende-se então, a necessidade de se pensar novas formas de mensurar o crescimento, a partir de um processo transparente e com participação da sociedade com vistas à uma tomada de decisão em busca do desenvolvimento sustentável.

A partir das discussões, verifica-se que o amparo legal viabilizou a criação de políticas públicas brasileiras, resultando em um sistema com características descentralizadoras, que responsabiliza a União, o Estado e os Municípios pela gestão ambiental. É nesse contexto de descentralização política que essas esferas devem estabelecer mecanismos e planejar ações conjuntas com a sociedade que busquem soluções às questões ambientais, por meio da implementação de políticas pública eficazes que gerem crescimento e que canalizem seus resultados à promoção da qualidade de vida para a sociedade (RODRIGUES et al., 2012).

\section{METODOLOGIA}

Esta pesquisa, de natureza qualitativa e de caráter descritivo e bibliográfico, surgiu a partir da seguinte indagação: o que se produz sobre Políticas Públicas Ambientais?

Para a realização do estudo, foram levantadas produções científicas nas bases eletrônicas de pesquisa Emerald, Scielo Citation Index, Science Direct e Scopus (Elsevier), publicadas a partir de estudos realizados sobre o tema "políticas públicas ambientais", nos últimos 15 (quinze) anos, para o qual se utilizou uma metodologia descritivo-analítico-reflexiva. Optou-se por não delimitar um período temporal, o que resultou em uma busca mais ampla nas bases selecionadas. 
O processo de investigação dos trabalhos esteve ancorado nos pressupostos da análise de conteúdo, que se baseia em operações de desmembramento do texto em unidades.

Trata-se de:

Um conjunto de técnicas de análise das comunicações visando obter, por procedimentos sistemáticos e objetivos de descrição do conteúdo das mensagens, indicadores (quantitativos ou não) que permitam a inferência de conhecimentos relativos às condições de produção/recepção (variáveis inferidas) destas mensagens (BARDIN, 2011).

Bardin (2011) enfatiza que a análise de conteúdo tem por objetivo a manipulação de mensagens (conteúdo e expressão desse conteúdo), para evidenciar os indicadores que permitam inferir sobre uma realidade que não a da mensagem. A partir de leituras minuciosas dos textos, buscou-se elementos comuns e divergentes, que possibilitam estabelecer relações e promover compreensões acerca do objeto de estudo.

A definição das buscas considerou os seguintes descritores 'políticas públicas ambientais' e 'meio ambiente e políticas públicas'. Todos os termos foram utilizados nos idiomas português, inglês e espanhol.

A pesquisa nas bases resultou em 22 (vinte e dois) artigos, sendo 2 (dois) na base de dados Emerald, 17 (dezessete) na Scielo Citation Index, 1 (um) na Science Direct e 2 (dois) na Scopus (Elsevier).

Após a leitura das 22 (vinte e dois) produções científicas foram detectadas um artigo repetido e duas publicações que não contemplavam o foco desta revisão sistemática. Ao final da seleção dos trabalhos levantados, conforme os critérios previamente estabelecidos, obteve-se um total de 12 (doze) trabalhos.

Para selecionar os artigos, o método utilizado foi o Teste de Relevância. O Teste de relevância possui três fases, sendo que, em cada fase são realizadas perguntas dicotômicas (sim ou não) para selecionar ou refutar o artigo científico. Quando da resposta de uma pergunta negativa, o artigo é descartado (PEREIRA et al., 2006).

Quadro 1: Caracterização dos Testes de Relevância.

\begin{tabular}{|l|l|}
\hline $\begin{array}{l}\text { Teste de } \\
\text { Relevância I }\end{array}$ & $\begin{array}{l}\text { O estudo aborda o tema de interesse para a investigação? O estudo foi publicado no período selecionado para a } \\
\text { investigação proposta pelos pesquisadores do projeto de pesquisa de Revisão Sistemática? O estudo foi } \\
\text { publicado em idioma selecionado para a investigação pelos pesquisadores, e determinado no projeto de pesquisa } \\
\text { de Revisão Sistemática? }\end{array}$ \\
\hline $\begin{array}{l}\text { Teste de } \\
\text { Relevância II }\end{array}$ & $\begin{array}{l}\text { Trata-se de um estudo que envolve diretamente seres humanos como sujeitos? O estudo está voltado para a } \\
\text { solução do problema específico que está sendo investigado? }\end{array}$ \\
\hline $\begin{array}{l}\text { Teste de de } \\
\text { Relevância III }\end{array}$ & $\begin{array}{l}\text { O objetivo do estudo tem relação com a questão que os avaliadores estão estudando no momento? A } \\
\text { metodologia empregada está suficientemente descrita, de forma que outros pesquisadores possam realizar o } \\
\text { mesmo estudo, de forma idêntica? A metodologia está adequada ao alcance dos objetivos? Os resultados são } \\
\text { compatíveis com a metodologia utilizada, merecendo credibilidade? A aplicabilidade dos resultados é possível na } \\
\text { prática, sendo que os benefícios se mostram superiores aos riscos potenciais e justificam os custos? }\end{array}$ \\
\hline
\end{tabular}

Fonte: Adaptado de Pereira et al. (2006).

\section{RESULTADOS E DISCUSSÃO}

Foram encontradas nas bases de dados mencionadas, um total de 20 (vinte) artigos. As produções duplicadas foram retiradas na análise manual, bem como as publicações aleatórias ao tema proposto.

Após a leitura dos textos dos artigos na íntegra, restaram 12 (doze) artigos, que foram lidos na sua totalidade e classificados aqueles que atenderam ao parâmetro de inclusão. As publicações que não receberam classificação nas categorias 1 (política pública ambiental) e 2 (meio ambiente e políticas públicas) foram excluídos, por não atenderem à questão norteadora da pesquisa A tabela 2 ilustra a busca nas bases. 
Tabela 1: Resultados dos levantamentos nas bases de dados.

\begin{tabular}{|c|c|c|c|c|c|}
\hline Base de Dados & $\begin{array}{l}\text { Publicações } \\
\text { Encontradas }\end{array}$ & Títulos e resumos lidos & Trabalhos incluídos & $\begin{array}{l}\text { Trabalhos } \\
\text { excluídos }\end{array}$ & Total \\
\hline Emerald & 2 & 2 & 0 & (2) & 0 \\
\hline Scielo Citation Index & 17 & 17 & 10 & (7) & 10 \\
\hline Science Direct & 1 & 1 & 1 & 0 & 1 \\
\hline Scopus (Elsevier) & 2 & 2 & 1 & (1) & 1 \\
\hline Trabalhos duplicados - Verificação manual & (1) & (1) & 0 & (1) & (1) \\
\hline Total Geral & & & & & 12 \\
\hline
\end{tabular}

Apesar das temáticas políticas públicas ambientais remeter ao pensamento de uma vasta produção científica sobre o assunto, o levantamento nas bases eletrônicas de pesquisa Emerald, Scielo Citation Index, Science Direct e Scopus (Elsevier) evidenciou o contrário. A pesquisa localizou 22 (vinte e dois) artigos que, após a leitura dos textos e a adoção de critérios de exclusão, foram selecionados 12 (doze) trabalhos que abordavam a proposta de estudo. Após a leitura dos textos, os mesmos foram fichados, com o objetivo de aproximar o pesquisador do seu material, afinal o conhecimento do corpus da pesquisa é essencial para categorizar estes textos de acordo com as características abordadas.

Tabela 2: Temática abordada pelos artigos analisados e respectiva frequência

\begin{tabular}{|c|c|c|c|}
\hline & Temática & Frequência & \\
\hline 1 & Desenvolvimento Sustentável & $A 1, A 2, A 3, A 5$ & 4 \\
\hline 2 & Formulação e implementação de políticas públicas ambientais & $A 1, A 2, A 3, A 6, A 7, A 8, A 9, A 10, A 11, A 12$ & 10 \\
\hline 3 & Gestão Ambiental & $A 1, A 4, A 5, A 6, A 7, A 8, A 9$ & 7 \\
\hline 4 & Legislação Ambiental / judicialização de Políticas Públicas & $A 1, A 2, A 5, A 6, A 9, A 12$ & 6 \\
\hline 5 & Participação social & $A 1, A 2, A 4, A 7, A 9$ & 5 \\
\hline 6 & Redes de pesquisa & A3 & 1 \\
\hline 7 & Sociedade de riscos / uso do solo & A4, A5 & 2 \\
\hline 8. & Gestão ambiental compartilhada & A7, A9 & 2 \\
\hline 9 & Gestão ambiental municipal/local & $A 7, A 8, A 12$ & 3 \\
\hline 10 & Percepção ambiental & $A 7, A 8, A 10$ & 3 \\
\hline 11 & Avaliação estratégica ambiental & A7 & 1 \\
\hline 12 & Política ambiental indígena & A9 & 1 \\
\hline 13 & Externalidades ambientais & A10 & 1 \\
\hline 14 & Área de Preservação Ambiental & A10 & 1 \\
\hline 15 & Passivo ambiental & A10 & 1 \\
\hline 16 & Resíduos sólidos eletrônicos & A11 & 1 \\
\hline 17 & Avaliação do ciclo de vida & A11 & 1 \\
\hline \multirow[t]{2}{*}{18} & Reciclagem & A11 & 1 \\
\hline & Total & & 51 \\
\hline
\end{tabular}

Os artigos analisados apresentaram discussões referentes as seguintes temáticas: desenvolvimento sustentável (A1, A2, A3, A5); formulação e implementação de políticas públicas ambientais (A1, A2, A3, A6, A7, A8, A9, A10, A11, A12); gestão ambiental (A1, A4, A5, A6, A6, A7, A8, A9); legislação ambiental (A1, A2, A5, A6, A12); participação social (A1, A2, A4, A7, A9); redes de pesquisa (A3), gestão de risco e uso do solo (A4 e A5); Gestão ambiental compartilhada (A7, A9); Gestão ambiental municipal/local (A7, A8, A12); Percepção ambiental (A7, A8, A10); Avaliação estratégica ambiental (A7); Política ambiental indígena (A9); Externalidades ambientais, Área de Preservação Ambiental e Passivo ambiental (A10); Resíduos sólidos eletrônicos, reciclagem e avaliação do ciclo de vida (A11).

A maior parte dos trabalhos apresentou, de forma direta, investigações sobre desenvolvimento sustentável; formulação, implementação e avaliação de políticas públicas; gestão ambiental; legislação ambiental e participação social. 
O desenvolvimento sustentável, como já mencionado no texto, envolve diversas interpretações, contudo, todas compartilham o entendimento de que este conceito está relacionado à qualidade de vida e a capacidade de suprir as necessidades da geração atual, sem comprometer a capacidade de atender as necessidades das futuras gerações, utilizando de forma racional os recursos naturais, aliando à questão político-econômica (ONU, 1987).

Conforme Leff (2006), o crescimento econômico, a equidade social e o meio ambiente são os três pilares do desenvolvimento sustentável que estão expressos na Constituição Federal de 1988 e nas demais legislações e políticas públicas sobre meio ambiente, assegurando a manutenção, gestão e fiscalização.

A gestão ambiental tem fundamental importância para o desenvolvimento sustentável, pois procura articular questões sociais e econômicas com a utilização racional dos recursos naturais, objetivando uma melhoria da qualidade de vida da população. Diante disso, para que a gestão ambiental aconteça, são necessárias ações efetivas e a formulação, implementação e avaliação de políticas públicas ambientais de forma adequada e com a participação da sociedade (NUNES et al., 2012).

A Política Nacional de Meio Ambiente e a Constituição Federal Brasileira, fornecem respaldo legal para a construção e consolidação de espaços de atuação da sociedade nas questões relacionadas ao meio ambiente, cabendo aos gestores a inclusão da participação social nas agendas ambientais (NEVES, 2016). Ainda, em relação à legislação ambiental, inseriu-se na temática sobre o protagonismo indígena, visto que esses povos são titulares do meio ambiente onde vivem e dele tiram o seu sustento (BRITO et al., 2015).

Outra temática abordada por um artigo foram as redes acadêmicas para pesquisas e capacitação em meio ambiente e desenvolvimento sustentável que, conforme a pesquisa, contribuem para o crescimento de formadores de opinião em favor de uma ciência mais integrada aos problemas reais e de um conhecimento como processo coletivo (COUTINHO et al., 2012).

A gestão do risco e o uso do solo foram propostas de pesquisa apresentada por dois artigos analisados que trazem uma reflexão sobre os riscos que a sociedade contemporânea criou, provenientes do desenvolvimento tecnológico e científico (VILLAR et al., 2009; ARROYAVE et al., 2009). Villar e Ribeiro (2009, p. 57) escrevem que: "Políticas públicas devem ter como metas a proteção da coletividade e se antecipar aos riscos [...] A gestão dos riscos está fundamentada em três elementos: a precaução, a prevenção e a indenização".

Considerando que a gestão ambiental, por meio das políticas públicas, assume papel primordial na proteção do meio ambiente, disciplinando atividades nocivas, promovendo formas adequadas de utilização do solo, garantindo desta forma a qualidade de vida das populações (VILLAR et al., 2009).

Outra temática abordada, discorreu sobre a gestão ambiental compartilhada e a percepção ambiental da população. Quando a população participa na formulação e implementação de políticas públicas para a gestão do meio ambiente, é possível uma contribuição mais ampla, visto que a população aponta as necessidades de mecanismos, de acordo com a percepção que possuem da realidade local, constituindo-se em uma gestão ambiental compartilhada (RODRIGUES et al., 2012; FERNANDES et al., 2012).

Entender o grau de percepção da comunidade sobre políticas ambientais e suas especificidades, 
contribui para melhores resultados para a sua criação, considerando as externalidades ambientais que ocorrem no âmbito do território municipal (FIGUEIREDO et al., 2016).

A temática sobre política pública ambiental local/municipal também foi alvo de discussão nos artigos analisados. Os municípios brasileiros são importantes atores no processo de formulação e implementação de políticas públicas ambientais, considerando a especificidade de cada município e o direcionamento local, possibilita o alcance da qualidade ambiental em nível global (RODRIGUES et al., 2012).

No entanto, a consolidação prática depende de fatores como os arranjos institucionais para se fazer cumprir as iniciativas adotadas; as regras do processo e os resultados; a capacidade de gasto, e; as diferenças inerentes à realidade de cada município. Esses fatores afetam a autonomia dos municípios, apresentandose, muitas vezes, precária (NEVES, 2016).

Verificou-se, também, um estudo que demonstra a importância de políticas públicas ambientais voltadas para a gestão de resíduos sólidos, mais especificamente, voltado à microcomputadores eletrônicos. A reciclagem e o aproveitamento das peças são o ponto de discussão, bem como a atribuição de responsabilidades para os fornecedores na logística reversa desses equipamentos no final de seu ciclo de vida, e maior atenção governamental para melhorar o aspecto ambiental nesse processo (ALCÁNTARA et al., 2016).

\section{CONCLUSÕES}

Dentre os 12 (doze) artigos selecionados para compor a amostra deste estudo de revisão sistemática, os resultados apontaram que há maior indício de pesquisas relacionadas às temáticas: desenvolvimento sustentável, formulação e implementação de políticas públicas ambientais, gestão ambiental, legislação ambiental/judicialização de políticas públicas e percepção ambiental. Isso significa que dentro do campo de políticas públicas ambientais, há uma maior preocupação com o desenvolvimento e implementação e a gestão dessas políticas, e até que ponto e, de que forma, a comunidade contribui para a formulação e o acompanhamento dessas políticas.

Como bem aponta Farah (2016), as publicações sobre políticas públicas no Brasil são recentes. No Brasil, uma maior concentração de publicações nessa área, deu-se a partir dos anos 2000, devido à oferta de cursos voltados às políticas públicas, institucionalizando esse campo de estudos. Essa carência de estudos é ainda mais evidente quando se trata de políticas públicas ambientais, e que consiste no achado desta pesquisa, considerando o baixo número de publicações encontrados nessa área.

Esta pesquisa limitou-se nos estudos publicados nas bases selecionadas, utilizando dos Testes de Relevância que resultaram na amostra selecionada. Sugere-se, futuramente, a ampliação deste estudo em outras bases de dados, bem como a exploração de temáticas mais específicas dentro das políticas públicas ambientais.

\section{REFERÊNCIAS}

ALCÁNTARA, V.; GAVILÁN-GARCÍA, A.; GAVILÁN-GARCÍA, I.

C.. Environmental Impacts at the end of life of computers and their management alternatives in México. Journal of Cleaner Production, v.131, p.615-628, 2016. 
ARROYAVE, S. M. S.; CORREA RESTREPO, F. J.. Análisis de la Contaminación del suelo: revisión de la normativa y posibilidades de regulación económica. Semestre Económico, v.12, n.23, p.13-34, 2009.

BARDIN, L.. Análise de Conteúdo. São Paulo: Edições 70, 2011.

BRASIL, F. G.; CAPELLA, A. C. N.. Os estudos das políticas públicas no Brasil: passado, presente e caminhos futuros da pesquisa sobre análise de políticas. Revista Política Hoje, v.25, n.1, p.71-90, 2016.

BRITO, A. L. C.; BARBOSA, E. M.. Protagonismo Indígena: o direito à consulta prévia e o modo de participação dos povos indígenas nos processos de criação e implementação de políticas públicas ambientais. Revista Espacios, v.36, n.21, p.1-11, 2015.

COUTINHO, S. M. V.; SAMPAIO, C. A. C.; PARRA O.; MALHEIROS, T. F.; FERNANDES, V.; PHILIPPI JUNIOR, A.. Redes acadêmicas para pesquisa e capacitação em meio ambiente e desenvolvimento sustentável: uma revisão crítica. Ambiente \& Sociedade, São Paulo, v.15, n.3, p.165184, 2012.

DEUBEL, A. N. R.. Enfoques para el análisis de las políticas públicas. Bogotá: Universidad Nacional del Colombia, 2010.

FARAH, M. F. S.. Análise de políticas públicas no Brasil: de uma prática não nomeada à institucionalização do "campo de públicas". Rev. Adm. Pública, Rio de Janeiro, v.50, n.6, p.959-979, 2016.

FERNANDES, V.; MALHEIROS, T. F.; PHILIPPI JUNIOR, A.; SAMPAIO, C. A. C. Metodologia de avaliação estratégica de processo de gestão ambiental municipal. Saúde Soc., São Paulo, v.21, n.3, p.128-143, 2012.

FIGUEIREDO, H. P.; CONSTANTINO, M. A.; SANCHES, C. C.; COSTA, R. B.. Environmental impacts of public policies in Campo Grande, MS: the case of Lajeado stream environmental protection area. Interações, Campo Grande, v.17, n.4, p.713-728, 2016.

FREY, K.. Políticas públicas: um debate conceitual e reflexões referentes à prática da análise de políticas públicas no Brasil. Planejamento e políticas públicas, Rio de Janeiro, n.21, p.211-259, 2000.

GUIMARÃES, R. P.; FEICHAS, S. A. Q.. Desafios na Construção de Indicadores de Sustentabilidade. Ambiente \& Sociedade, Campinas, v.12, n.2, p.307-323, 2009.

HOCHMAN, G.; ARRETCHE, M.; MARQUES, E.. Políticas Públicas no Brasil. Rio de Janeiro: Fiocruz, 2007.

LEFF, E.. Racionalidade ambiental: a reapropriação social da natureza. Rio de Janeiro: Civilização Brasileira, 2006.

MENY, Y.; THOENIG, J-C.. Las políticas públicas. Barcelona: Ariel, 1992

MONOSOWSKI, E.. Políticas ambientais e desenvolvimento no Brasil. Cadernos FUNDAP, São Paulo, v.9, n.16, p.15-24, 1989.

NEVES, E. M. S. C.. Institutions and environmental governance in Brazil: the local governments' perspective. REC, v.20, n.3, p.492-516, 2016.

NUNES, M. R.; PHILIPPI JUNIOR, A.; FERNANDES, V.. A Atuação de Conselhos do Meio Ambiente na Gestão Ambiental Local. Saúde Soc., São Paulo, v.21, n.3, p.4860, 2012.

ONU. Organização das Nações Unidas. Meio Ambiente. Comissão Brundtland. ONU, 1987.

PECCATIELLO, A. F. O.. Políticas públicas ambientais no Brasil: da administração dos recursos naturais (1930) à criação do Sistema Nacional de Unidades de Conservação (2000). Desenvolvimento e Meio Ambiente, n.24, p.71-82, 2011.

PEREIRA, A. L.; BACHION, M. M.. Atualidades em revisão sistemática de literatura, critérios de força e grau de recomendação de evidência. Rev. Gaúcha Enferm., Porto Alegre, v.27, n.4, p.491-498, 2006.

RODRIGUES, M. L.; MALHEIROS, T. F.; FERNANDES, V.; DARÓS, T. D.. A percepção ambiental como instrumento de apoio na gestão e na formulação de políticas públicas ambientais. Saúde Soc., São Paulo, v.21, n.3, p.96-110, 2012.

SACHS, I.. Desenvolvimento: includente, sustentável, sustentado. Rio de Janeiro: Garamond, 2004.

SACHS, I.. Rumo à ecossocioeconomia: teoria e prática do desenvolvimento. São Paulo: Cortez, 2007.

SARAVIA, E.. Introdução à teoria da política pública. In: SARAVIA, E.; FERRAREZI, E.. Políticas públicas. Brasília: ENAP, 2006. p.21-42.

SMITH, K. B.; LARIMER, C. W.. The public policy theory primer. New York: Westview Press, 2009.

SOUZA, C.. Políticas públicas: uma revisão da literatura. Sociologias, Porto Alegre, n.16, p.20-45, 2006.

VASCONCELLOS, M. A. S.; TROSTER, R. L.. Economia básica: teoria e exercícios. 4 ed. São Paulo: Atlas, 1998.

VILLAR, P. C.; RIBEIRO, W. C.. Sociedade e gestão do risco: o aquífero Guarani em Ribeirão Preto, SP, Brasil. Revista de Geografia Norte Grande, v.43, p.51-64, 2009.

A CBPC - Companhia Brasileira de Produção Científica (CNPJ: 11.221.422/0001-03) detém os direitos materiais desta publicação. Os direitos referem-se à publicação do trabalho em qualquer parte do mundo, incluindo os direitos às renovações, expansões e disseminações da contribuição, bem como outros direitos subsidiários. Todos os trabalhos publicados eletronicamente poderão posteriormente ser publicados em coletâneas impressas sob coordenação da Sustenere Publishing, da Companhia Brasileira de Produção Científica e seus parceiros autorizados. Os (as) autores (as) preservam os direitos autorais, mas não têm permissão para a publicação da contribuição em outro meio, impresso ou digital, em português ou em tradução. 